\title{
An assessment of the quality of near-real time GNSS observations as a potential data source for meteorology
}

\author{
Natalia Dymarska, Witold Rohm, Jan Sierny, Jan Kapłon \\ Wroctaw University of Environmental and Life Sciences, Institute of Geodesy and Geoinformatics, Grunwaldzka 53, \\ 50-357 Wroctaw, Poland, e-mail: natalia.dymarska.igig@gmail.com
}

\section{Tomasz Kubik}

Wroctaw University of Science and Technology, Department of Computer Engineering, Faculty of Electronics, Wybrzeże Wyspiańskiego 27, 50-370 Wrocław, Poland

\author{
Maciej Kryza \\ University of Wrockaw, Department of Climatology and Atmosphere Protection, Poland
}

\author{
Jerzy Jutarski, Jacek Gierczak, Ryszard Kosierb \\ Institute of Meteorology and Water Management - National Research Institute, Parkowa 30, 51-616 Wrocław, Poland
}

\begin{abstract}
The Global Navigation Satellite System (GNSS) can be used to determine accurate and high-frequency atmospheric parameters, such as Zenith Total Delay (ZTD) or Precipitable Water Vapour $(P W)$, in all-weather conditions. These parameters are often assimilated into Numerical Weather Prediction (NWP) models and used for nowcasting services and climate studies. The effective usage of the ZTDs obtained from a ground-based GNSS receiver's network in a NWP could fill the gap of insufficient atmospheric water vapour state information.

The supply of such information with a latency acceptable for NWP assimilation schemes requires special measures in the GNSS data processing, quality control and distribution. This study is a detailed description of the joint effort of three institutions - Wrocław University of Environmental and Life Sciences, Wrocław University, and the Institute of Meteorology and Water Management - to provide accurate and timely GNSS-based meteorological information. This paper presents accuracy analyses of near real-time GNSS ZTD validated against reference ZTD data: the International GNSS Service (IGS) from a precise GNSS solution, Weather Research and Forecasting (WRF) model, and radiosonde profiles. Data quality statistics were performed for five GNSS stations in Poland over a time span of almost a year (2015). The comparison of near real-time ZTD and IGS shows a mean ZTD station bias of less than $3 \mathrm{~mm}$ with a related standard deviation of less than $10 \mathrm{~mm}$. The bias between near real-time ZTD and WRF ZTD is in the range of 5-11 mm and the overall standard deviation is slightly higher than $10 \mathrm{~mm}$. Finally, the comparison of the investigated ZTD against radiosonde showed an average bias at a level of $10 \mathrm{~mm}$, whereas the standard deviation does not exceed $14 \mathrm{~mm}$. Considering the data quality, we assess that the NRT ZTD can be assimilated into NWP models.
\end{abstract}

Keywords: ZTD estimation, data validation, GNSS meteorology

Submitted 1 March 2016, revised 30 June 2016, accepted 8 September 2016

\section{Introduction}

GNSS has revolutionised the way we commute, work and travel, and has also changed land and engineering surveying methodologies (Bosy et al. 2007). One of the great benefits to surveying professionals offered by GNSS technology is almost instantaneous, real-time, centimetre-level positioning accuracy across the whole country (Hofmann-Wellenhof et al. 2008). However, this solution comes brings with it costs to ground infrastructure: 1) a network of GNSS reference stations with limited inter- station distances, of e.g., $60-70 \mathrm{~km}$; 2) high-speed internet connection between the stations and processing centres; 3) high computing power processing centres able to resolve a system of normal equations in real-time for hundreds of stations and provide corrections or observations to rover users (Landau et al. 2002).

There are two major types of such infrastructure in Poland: state-owned and privately-owned. The former is provided, maintained and operated by the Head Office of Geodesy and Cartography and forms part of the national reference frame, important for sustaining the connection 
between state and European references frames (Bosy et al. 2007). In this ASG-EUPOS network (Active Geodetic Network EUPOS), raw GNSS data is offered for free to scientific users. The latter type, i.e., owned by private companies (such as Leica's SmartNet or VRS.net) are operated by major distributors of surveying equipment and their data access is based on individual agreements. Currently, there are at least 400 stations in Poland observing GNSS signals involving at least two satellite systems (GPS and GLONASS), and all these stations are built and maintained to improve positioning accuracy of its rover users; hence the reuse of the same observations for other purposes, such as meteorology, is an additional benefit.

One of the main limitations of current positioning technologies is of the lack of knowledge of GNSS signal interaction with a propagation environment - i.e., how the signal travelling from the GNSS satellites to the receiver is attenuated, slowed down and bent (Hofmann-Wellenhof et al. 2008). These effects are different between the troposphere and ionosphere. The signal phase in the ionosphere is delayed and group velocity is advanced selectively for different frequencies (Hoque, Jakowski 2007), while in the troposphere both phase and group velocity of a GNSS signal is delayed regardless the frequency (Norman et al. 2015). In this study we only focus on the latter. The tropospheric effects on GNSS signal propagation are very challenging to be modelled as these effects are non-dispersive with respect to the frequency. The only strategy to quantify the effect is to estimate special tropospheric parameters along with other geodetic parameters (like coordinates) in the common network solution (Rohm et al. 2014). This is the main concept of ground-based GNSS. This parameter is called Zenith Troposphere Delay (ZTD). The ZTD is estimated for each station in the network at selected time intervals and is an excellent observation of the state of the troposphere (Hordyniec et al. 2015).

The GNSS signal troposphere delay between a satellite and a receiver is a function of the density of air and the bending of the signal from the satellite above 10 degrees is marginal. It slows down (i.e., delays) the signal propagation. Hence, the delay due to refraction according to the Thayer equation is equal to (Solheim et al. 1999):

$$
Z T D=10^{-6}\left(\int N_{d} d s+\int N_{w} d s\right)
$$

where: $N_{d}$ is the dry refractivity and $N_{w}$ is the wet refractivity that is associated with pressure, temperature and water vapour respectively. The delay is a function of pressure, temperature and water vapour content of the troposphere. Thus, the precise knowledge of pressure and temperature is needed for water vapour-related parameters (from the meteorological perspective), i.e., Integrated Water Vapour $(I W V)$, or Precipitable Water $(P W)$ (Kleijer 2004). These parameters are usually calculated from radiosonde profiles (twice a day) or NWP fields (Zheng et al. 2013). Using GNSS, one can almost directly measure $I W V$ or $P W$ along with additional pressure and temperature information (Hordyniec et al. 2015).

In this study we would like to show a near real-time ZTD estimation (shown in section 2.1 to 2.4 ), and a storage and distribution system (section 2.5 ) running operationally at Wrocław University of Environmental and Life Sciences. The complex processing and quality assurance system was based on a radiosonde and reference GNSS solution. We have computed statistics for almost one year's data for 5 stations located in Poland and put in place quality assurance procedures. The data and estimation system are laying the foundations for near real-time assimilation of GNSS data in weather models across Poland, the application of estimated parameters to climate studies and also weather nowcasting. The results of the cross comparison of multiple data sources are presented in section 3, followed by discussion and future work, which is shown in section 4. Conclusions are given in section 5 .

\section{Methodology}

The methodology for estimating ground-based GNSS troposphere delays in post-processing and near real-time mode, as well as procedures for calculating the delay from meteorological observations, are presented below. There are also descriptions of three database systems, which store ZTD data.

\subsection{Estimation of $Z T D$ by IGS in Precise mode}

The International GNSS Service (IGS) is a voluntary federation of over 200 self-funding agencies, universities and research institutions in more than 100 countries; it is designed to maintain an independent ground tracking network and generate high quality products. IGS products and services support the realisation of the International Terrestrial Reference Frame (ITRF), Earth observations and research, positioning, navigation and timing, and other applications for the benefit of any researcher (Dow et al. 2009). This service is an important component of the Global Geodetic Observing System (GGOS; Dow et al. 2009). IGS data and products are available to all users and include: GNSS satellite ephemerides, Earth rotation parameters, tracking station coordinates/velocities, satellite and tracking station clock information, zenith tropospheric path delay estimates and global ionosphere maps 
(Hackman et al. 2015). Since April 2011 the Troposphere Working Group of the IGS has produced a high-precision GPS-based troposphere product known as the IGS Final Troposphere Product. The current version of this product is estimated at the United States Naval Observatory (USNO).

IGS Final Troposphere Estimates (IGS FTE) of the Zenith Path Delay involve Zenith Tropospheric Delays (ZTD), gradients (GE, GN), and its formal errors for most of the stations of the IGS network. IGS Final Troposphere estimates are generated via Bernese GPS Software 5.0 (Möller et al. 2014). USNO uses a precise point positioning (PPP) approach in the form of a 27-hour observation window to process undifferenced GNSS observations (Byram, Hackman 2012). This PPP processing utilises the GMF mapping function with IGS Final satellite orbits/ clocks and Earth orientation parameters as an input. The lowest elevation angle cutoff is defaulted 7 degrees, but this value depends on the type of receiver. Each receiver has its own cutoff angle and the angle observations lower than 7 are ignored in processing. The estimates are provided on a daily basis in the SINEX tropo format with a temporal resolution of $5 \mathrm{~min}$. The relative a priori sigmas are $1 \mathrm{~mm}$ for the ZTD and $0.1 \mathrm{~mm}$ for gradients. As reported by Byram and Hackman (2012), the station coordinate repeatability associated with the IGS FTE is on average less than $2 \mathrm{~mm}$ in the north $(\mathrm{N})$ direction, and about $3 \mathrm{~mm}$ in the east (E) direction and greater than $5 \mathrm{~mm}$ in the up (U) component. Each site-day's processing results are completed approximately three weeks after the measurement collection, as the IGS Final orbit products become available. IGS FTE files can be downloaded from ftp://cddis.gsfc.nasa.gov/gps/products/troposphere/zpd (Hackman et al. 2015).

\subsection{ZTD estimated from GNSS in NRT mode at WUELS}

The Institute of Geodesy and Geoinformatics at WUELS (Wrocław University of Environmental and Life Sciences) hosts the NRT service estimating the ZTD and its horizontal gradients using the GPS data from the area of Poland and close neighbourhood. The stations belong to the EUREF Permanent Network, ASG-EUPOS and Leica SmartNet networks. The processing engine is based on Bernese GNSS Software v. 5.2 (Dach et al. 2015) supported by the Perl scripts developed at WUELS for processing automation and the dissemination of the results. From December 2012 to April 2015, the NRT service (Bosy et al. 2012) was based on Bernese GPS Software v.5.0 (Dach et al. 2007). The main processing parameters and constraints are presented in Table 1.

The NRT processing procedure contains the following steps: reference coordinate estimation using the last two weeks' solutions, GNSS raw data check and conversion to Bernese internal format, Single Point Positioning (SPP) using code data for clock synchronisation, forming the baselines (single and double differences of code and phase observations) using the OBSMAX strategy (Dach et al. 2015), phase observation screening, resolving of ambiguity, parameter estimation (coordinates and troposphere), preparation of resultant COST-716 files and their upload to the WUELS database.

\subsection{ZTD calculated from WRF data}

Predicted meteorological data (i.e. the pressure, temperature and humidity forecasts) are generated by the computing services of the University of Wrockaw using the WRF model grid cells for the position of the stations. The

Table 1. WUELS NRT service processing parameters

\begin{tabular}{|c|c|c|}
\hline Parameters & Bernese GPS Software v. 5.0 & Bernese GNSS Software v. 5.2 \\
\hline Period of use & December 2012 - April 2015 & Starting from September 2015 \\
\hline Number of stations & 123 & 250 \\
\hline Elevation cut-off angle & $5^{\circ}$ & $5^{\circ}$ \\
\hline Orbit/Clock/ERP & IGS or CODE Ultra-Rapid & IGS or CODE Ultra-Rapid \\
\hline Processed window length & $12 \mathrm{~h}$ & $6 \mathrm{~h}$ \\
\hline GPS phase ambiguity handling & $\begin{array}{l}\text { Estimation using L5 and L3 signal with } \\
\text { SIGMA algorithm (Dach et al. 2007) }\end{array}$ & $\begin{array}{l}\text { Baseline length dependent estimation (L6/L3, L1/L2, L5/L3 with } \\
\text { SIGMA strategy, L1/L2 with QIF strategy) (Dach et al. 2015) }\end{array}$ \\
\hline $\begin{array}{l}\text { Interval of troposphere } \\
\text { parameter estimation }\end{array}$ & $30 \min$ & $30 \mathrm{~min}$ \\
\hline $\begin{array}{l}\text { Troposphere a-priori model/ } \\
\text { mapping function (MF) }\end{array}$ & $\begin{array}{l}\text { Saastamoinen (1972) dry part only/ } \\
\text { Dry Niell MF (Niell 2000) }\end{array}$ & $\begin{array}{l}\text { Saastamoinen (1972) Dry part only/ } \\
\text { Dry Global MF (Boehm et al. 2006) }\end{array}$ \\
\hline \multirow{2}{*}{$\begin{array}{l}\text { Site-specific troposphere } \\
\text { parameters }\end{array}$} & $Z W D$ - estimated using Wet Niell MF & $Z W D$ - estimated using Wet Global MF \\
\hline & $Z T D$ gradients (none) & Horizontal ZTD gradients (Chen, Herring 1997) \\
\hline $\begin{array}{l}\text { Relative troposphere param- } \\
\text { eters constraining }\end{array}$ & ZTD: $3 \mathrm{~mm}$ & $Z T D: 2 \mathrm{~mm}$, and gradients: $0.2 \mathrm{~mm}$ \\
\hline
\end{tabular}


model is run every 6 hours and gives time series with a 24hour lead time and 1 hour resolution. The model domain has 48 vertical levels and a $4 \times 4 \mathrm{~km}$ horizontal resolution. The time series are delivered using NCAR Command Language (ncl) (NCAR 2016) in the form of a pair of text files to the LIGiG system with the use of web disk - a service offered by the Wrocław Centre for Networking and Supercomputing. The LIGiG System reads the delivered data files regularly and computes $Z T D, Z W D$ and $Z H D$ values. It is able to handle situations of delayed delivery or missing files. During computation it also uses data available from the database maintained by IGIG. The ncl-generated files are surface_(data generated at the level of particular stations) and profile_ (with data generated at the layers of the vertical profile) and contains date, time, station ID, latitude, longitude, and height of the station (surface_), height of the model layer (profile_), temperature [K], pressure $[\mathrm{hPa}]$, and relative humidity [\%] at the location of the station (surface_) or in the vertical profile above the station (profile_). The LIGiG System computes ZTD values using the precise method described below. The procedure starts after a new pair of files (surface_and profile_) is delivered to the web disk. For each record of the generated time series (i.e., for every hour and for every station), the $Z T D$ value is computed from the rule:

$$
Z T D=Z H D+Z W D
$$

The hydrostatic part is calculated based on the Saastamoinen (1972) formula and the data from a surface_file:

$$
Z H D=\frac{0.0022768 \cdot P}{1-0.0026 \cdot \cos (2 \phi)-0.00000028 \cdot h}
$$

where: $\phi$ is the geodetic latitude of the station, $h$ is the geoidal height of the station, $P$ is the atmospheric pressure taken directly from the surface_ file (if ncl was able to calculate one) or from the following interpolation (if ncl cannot calculate one), according to the Karabatić et al. (2011) formula:

$$
P=P_{s}\left(\frac{T_{s}-\gamma\left(h-h_{s}\right)}{T_{s}}\right)^{\frac{g \cdot M}{R \cdot \gamma}}
$$

where: $p_{s}, T_{s}, h_{s}$ are the pressure, temperature and height corresponding to the WRF model; $\gamma=0.0065[\mathrm{~K} / \mathrm{m}]$ represents the gradient of temperature; $M=0.0289644[\mathrm{~kg} / \mathrm{mol}]$ is the molar mass of dry air; $R=8.31432[\mathrm{~N} \cdot \mathrm{m} /(\mathrm{mol} \cdot \mathrm{K})]$ is the gas constant for ideal gas; $g$ is the gravitational acceleration modified by Hitsch (2004). The calculation of the ZWD value is obtained by integrating the wet refractivity $N_{w}$.

$$
Z W D=10^{-6} \cdot \int_{H 0}^{\infty} N_{w}(H) d H
$$

The discrete form of this equation:

$$
Z W D=10^{-6} \cdot \sum_{i=1}^{M} N_{w}(i) \cdot \Delta s(i)
$$

where:

$$
N_{w}(i)=Z_{v}^{-1} \cdot\left(k_{2}{ }^{\prime} \frac{e(i)}{T(i)}+k_{3} \frac{e(i)}{T^{2}(i)}\right)
$$

represents wet refractivity. The associated temperature is calculated from the data from in the profile file for the $i$-th layer of the WRF model. The constants used are $Z_{v}^{-1} \approx 1, k_{2}{ }^{\prime}=17 \pm 10\left[\mathrm{~K} \cdot \mathrm{hPa}^{-1}\right], k_{3}=3.776 \pm 0.004 \cdot 10^{5}\left[\mathrm{~K} \cdot \mathrm{hPa}^{-1}\right]$. $T(i)$ represents temperature on the $i$-th layer of the WRF model (from the profile_file) and $e(i)$ represents water vapour pressure. $\Delta s(i)$ is the thickness of the $i$-th layer given by: for $i=0 \Delta s(i)=h_{i}-h$ (the thickness of the lowest layer is the difference between the station's normal height (data from surface_file) and the height of the layer (data from the profile_file)) and $\Delta s(i)=h_{i}-h_{i-1}$ for $i>0$ (the thickness of the other layers is calculated as the difference between the heights of two consecutive layers - data from the profile_file); $M$ is the number of layers in the model.

The LIGiG System derives the time series of ZTD values from the corresponding meteorological time series data stored in the delivered files. Let $Q_{k}$ denote the time series of meteorological data generated from the WRF model for a station at time $k$ (such series are generated every $6 \mathrm{~h}$ and have a $24 \mathrm{~h}$ lead time and $1 \mathrm{~h}$ resolution), then:

$$
Q_{k}=\left(q_{k, j}\right), k=0,6,12,18,24, \ldots, j=0,1,2, \ldots, 23
$$

Let $Z_{k}$ denote the series of $Z T D$ values computed from data records of $Q_{k}$ :

$$
Z_{k}=\left(z_{k, j}\right), z_{k, j}=f\left(q_{k, j}\right)
$$

The series of weighted mean ZTD values can be expressed as:

$$
\bar{Z}=\left(\bar{z}_{l}\right), z_{l}=\frac{\sum_{k+j=l} z_{k, j} \cdot w_{k, j}}{\sum_{k+j=l} w_{k, j}} w_{k, j}=\frac{1}{j+2}
$$

where $l=0,1,2, \ldots$ represents the time stamp at which the weighted mean $Z T D$ is computed.

It should be noted that the elements of the $\bar{Z}$ series, i.e., $\bar{z}_{l}$, are calculated from at most four different ZTD series that are related to the same time stamp (see Fig. 1).

The first step of the computation is done by calculating the weighted sum of all ZTD values received from 


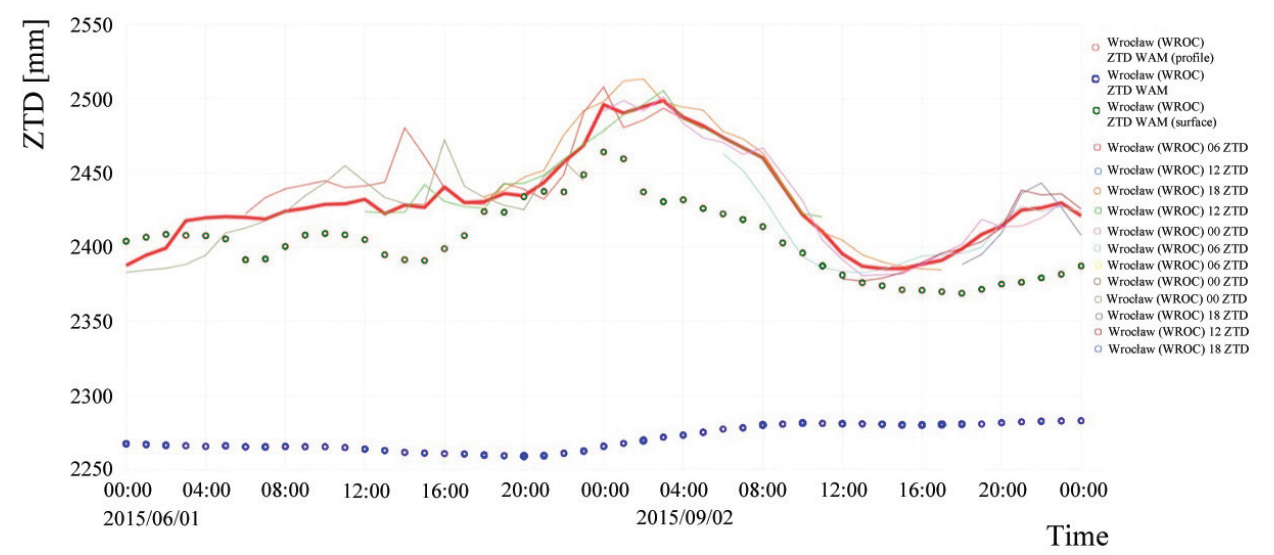

Fig. 1. The picture shown by the LIGiG system. The thick red line represents the Weighted Average Mean (WAM) ZTD of forecasts. The red circles represent the starting time of forecasts and thin color lines show the computed ZTD for a given time series. The green circles represent $Z T D$ based on the simple Saastamoinen approach, and the blue circles represent $Z H D$

the processing of the weather forecast data and available for the moment $l$; and the weight value decreases with the increase of the index of ZTD value (newer values should have greater weight: $w_{0,0}=1 / 2, w_{0,1}=1 / 3, w_{0,2}=1 / 4, \ldots$ ). For example, the $Z T D$ value for hour 19.00 UTC is:

$$
\bar{z}_{19}=\frac{z_{0,19} \cdot w_{0,19}+z_{6,13} \cdot w_{6,13}+z_{12,7} \cdot w_{12,7}+z_{18,1} \cdot w_{18,1}}{w_{0,19}+w_{6,13}+w_{12,7}+w_{18,1}}
$$

\subsection{ZTD calculated from radiosonde data}

The radiosonde (RS) data from 3 launching sites, WROCLAW, LEGIONOWO, and LEBA, are downloaded from the World Meteorological Organization service provided by the National Oceanic and Atmospheric Administration (NOAA) on the website: http://esrl.noaa.gov/raobs/. They are automatically downloaded in $12 \mathrm{~h}$ intervals using Perl scripts. The profiles of atmosphere pressure, temperature and water vapour are screened for outliers and blunders, and then the station heights are verified and transformed from geoid to ellipsoid. Different procedures for the calculation of $Z H D$ and $Z W D$ are used. For the hydrostatic part, the data of pressure and temperature from the ground level of radiosonde launch sites are read and interpolated in the vertical direction to the height of the GNSS station using equation (4). The pressure is then applied in the Saastamoinen model (equation 3). The next step comprises interpolation of temperature and water vapour to the common high density vertical grid. The $Z W D$ is calculated as the sum of wet refractivities (equation 7) along the vertical ascending path of a weather balloon multiplied by the thickness of the vertical levels (equation 6). Finally, the ZTD is the sum of the $Z W D$ and $Z H D$. These data are stored in a database for the use of near real-time ZTD quality assessment and future post-processing.

\subsection{Database systems MaGDA, c-MaGDA and LIGiG}

The three databases, MaGDA, c-MaGDA and LIGiG, established to support GNSS meteorology activities at WUELS are associated with 3 different projects, thus they are different in their architecture and Database Management Systems.

MaGDA (Meteo and GNSS Data Access) was started in 2011 at WUELS to provide quick and easy access to meteorological and GNSS data, and to allow the analysis and assimilation of the data. All sources of the data, along with their precise locations, are catalogued in this database. We gather data for: 1) calculation of ZTD data, gradients (north and east) and their errors from GNSS data of all stations (ca. 295) in the ASG and Leica SmartNET networks in NRT mode - from year 2012; 2) meteorological data from three types of sources: METAR - from year 2011, SYNOP - from year 2013, ASG - from year 2013; 3) lightning strikes from year 2015. All data are updated automatically as soon as access to the data is available. GNSS and meteorological data are updated once an hour and lightning strike data have a maximum 10-minute delay.

c-MaGDA was launched in the second half of 2015. The data are collected from USNO Analysis Center for IGS Final Troposphere Estimates (USNO table) and from the WMO service for radiosonde data (radiosonde table). ZTD data, gradients (north and east) and their errors in the USNO table are calculated every day (with three weeks' latency) for the five IGS stations in Poland: BOGI, BOR1, JOZE, LAMA and WROC. Data for the radiosonde table are input twice a day (every 12 hours) for three radiosonde stations in Poland: LEBA (12120), LEGIONOWO (12374) and WROCLAW (12425), and then the ZTD data are interpolated to the nearest GNSS stations. The Radiosonde table stores $Z T D, Z H D$ and $Z W D$ values. The USNO 
table contains IGS ZTDs from 1 January 2012, whereas the radiosonde table includes data from 1 December 2012

The LIGiG database system was launched at the Wrocław University of Technology in June 2015. In this database, the data are selected data from WRF run experimentally by Wrocław University for all GNSS stations in Poland processed by WUELS (currently more than 250 stations). The information stored in this database are: temperature $[\mathrm{K}]$, pressure $[\mathrm{hPa}]$, relative humidity $[\%]$ at the location of the GNSS stations and in the vertical profile above the station. Temporally averaged $Z H D$ s, $Z W D$ s and $Z T D$ s are stored in one table. This database is updated regularly at 6-hour intervals.

\section{Quality of NRT $Z T D$}

In order to assess the quality of the ZTD derived from GNSS in the near real-time mode, we compared it with three reference ZTD sources from IGS in Precise mode (USNO), WRF data (LIGIG) and radiosonde data (RS). Nearly a year (from 20 February 2015 to 31 December 2015) of ZTDs for five GNSS stations in Poland are analysed (Fig. 2).

The time spans covered by different data source differs (Fig. 2, right panel) as the data sources are funded by different projects and initiatives i.e.: 1) WUELS ZTDs (blue line) are routinely processed by our WUEL E-GVAP centre, but from April to September we were redeveloping our processing engine and switching from Bernese 5.0 to Bernese 5.2; 2) LIGIG (red) is a service developed within the SPIN-LAB project that aims to deliver e-tools for scientists with the data source being the WRF model run experimentally by Wrocław University and undergoing frequent modifications. LIGIG provides ZTDs for locations processed by WUELS, hence the green line represents stations introduced to the WUELS processing in mid-August 2015; 3) USNO (grey) shows the official IGS product available for stations WROC and BOGI over the whole year; 4) RS data (orange) are available all year round.

Using these data, we calculate the differences between the $Z T D$ s from the four data sources, $Z T D_{\text {wUELS }}-Z T D_{\text {USNO }}$, $Z T D_{\text {WUELS }}-Z T D_{\mathrm{RS}}, Z T D_{\text {WUELS }}-Z T D_{\text {LIGIG }}, Z T D_{\mathrm{RS}}-Z T D_{\text {USNO }}$, $Z T D_{\text {LIGIG }}-Z T D_{\text {USNo }}$ and their statistics, i.e., biases (equation 12), and standard deviations (equation 13):

$$
\begin{gathered}
B I A S=\frac{1}{n} \sum_{i=1}^{n} \mu_{i}^{2} \\
S T D=\sqrt{\frac{1}{n} \sum_{i=1}^{n}\left(\mu_{i}-m\right)^{2}}
\end{gathered}
$$

where: $\mu$ is the value of the difference between estimated or observed ZTD and reference $Z T D, m$ is the mean value of the differences, and $n$ is the sample size. Table 2 provides these statistics for each station. Additionally, the values of differences at WROC station for the whole period are also shown (Fig. 3).

The collocated ZTD differences show that each source of the ZTD has a systematic error (bias) in comparison to the reference data. The highest standard deviation is observed from the WUELS-LIGIG comparison, whereas the greatest bias is much more difficult to pinpoint - all data sources are affected. The systematic errors of the WUELSUSNO and RS-USNO values for all the stations are negative, whilst the biases between LIGIG-USNO are positive. The bias between $Z T D_{\text {WUELS }}$ and $Z T D_{\mathrm{RS}}$ is positive and negative compared with the pair of $Z T D_{\text {WUELS }}$ and $Z T D_{\text {USNO. }}$ The standard deviations of RS-USNO are a little better than for RS-WUELS. In the case of the LIGIG data, the bias values are negative from the WUELS reference data, whereas positive from the USNO. The statistics results for LIGIG, similar to radiosonde, are better for USNO reference data than for WUELS. The best statistical results are from the WUELS-USNO comparison. This means that both biases and standard deviations have the lowest values for these data, i.e., a mean value of these statistics is $-2.58 \mathrm{~mm}$ for bias and $6.73 \mathrm{~mm}$ for STD.

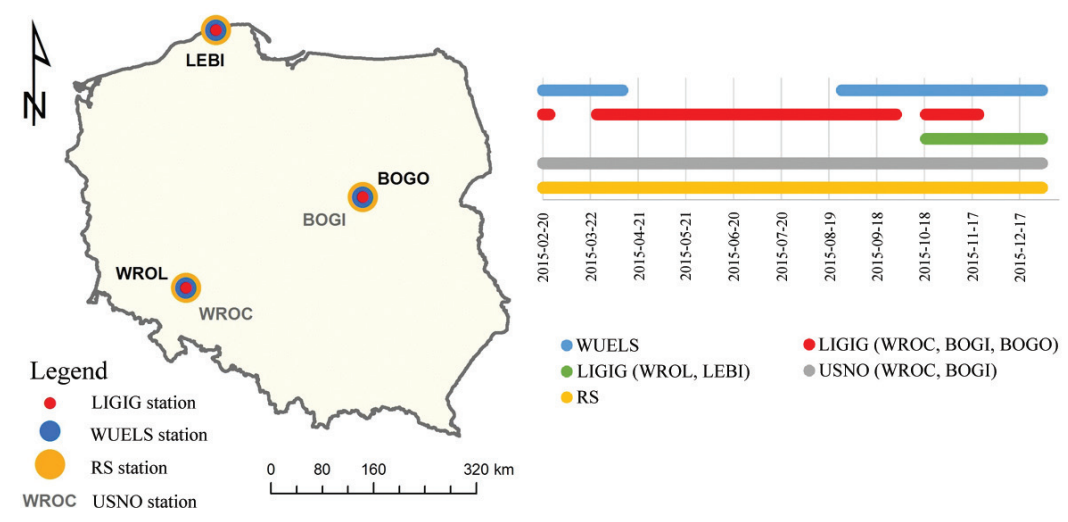

Fig. 2. Distribution of the WUELS, LIGIG, USNO and RS stations (left panel) and ZTDs availability (right panel) in the period from 20 February 2015 to 31 December 2015 
Table 2. Biases, standard deviations and sample sizes of the values of $Z_{T} D_{\mathrm{WUELS}}-\mathrm{ZTD}_{\mathrm{USNO}}, \mathrm{ZTD}_{\mathrm{WUELS}}-\mathrm{ZTD}_{\mathrm{RS}}, \mathrm{ZTD}_{\mathrm{WUELS}}-\mathrm{ZTD}_{\mathrm{LIGIG}}$,

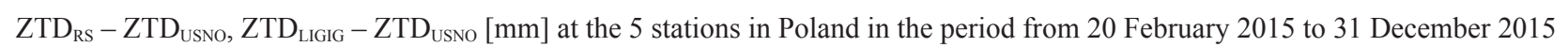

\begin{tabular}{|c|c|c|c|c|c|c|c|c|c|c|c|c|c|c|c|}
\hline \multirow{2}{*}{ 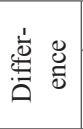 } & \multicolumn{3}{|c|}{ WROC } & \multicolumn{3}{|c|}{ BOGI } & \multicolumn{3}{|c|}{ BOGO } & \multicolumn{3}{|c|}{ WROL } & \multicolumn{3}{|c|}{ LEBI } \\
\hline & $\begin{array}{l}\text { BIAS } \\
{[\mathrm{mm}]}\end{array}$ & $\begin{array}{l}\text { STD } \\
{[\mathrm{mm}]}\end{array}$ & $\begin{array}{c}\text { sample } \\
\text { size }\end{array}$ & $\begin{array}{l}\text { BIAS } \\
{[\mathrm{mm}]}\end{array}$ & $\begin{array}{l}\text { STD } \\
{[\mathrm{mm}]}\end{array}$ & $\begin{array}{c}\text { sample } \\
\text { size }\end{array}$ & $\begin{array}{l}\text { BIAS } \\
{[\mathrm{mm}]}\end{array}$ & $\begin{array}{l}\text { STD } \\
{[\mathrm{mm}]}\end{array}$ & $\begin{array}{c}\text { sample } \\
\text { size }\end{array}$ & $\begin{array}{l}\text { BIAS } \\
{[\mathrm{mm}]}\end{array}$ & $\begin{array}{l}\text { STD } \\
{[\mathrm{mm}]}\end{array}$ & $\begin{array}{c}\text { sample } \\
\text { size }\end{array}$ & $\begin{array}{l}\text { BIAS } \\
{[\mathrm{mm}]}\end{array}$ & $\begin{array}{l}\text { STD } \\
{[\mathrm{mm}]}\end{array}$ & $\begin{array}{c}\text { sample } \\
\text { size }\end{array}$ \\
\hline 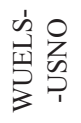 & -2.82 & 5.93 & 7294 & -2.34 & 7.53 & 6929 & NA & NA & NA & NA & NA & NA & NA & NA & NA \\
\hline 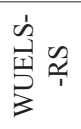 & 11.25 & 11.17 & 308 & 3.47 & 11.30 & 291 & 6.27 & 11.23 & 313 & 13.16 & 11.49 & 146 & 8.43 & 9.91 & 101 \\
\hline 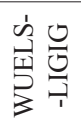 & -8.55 & 11.36 & 1766 & -10.66 & 12.37 & 1563 & -10.63 & 11.63 & 1780 & -5.88 & 11.21 & 608 & -0.01 & 10.25 & 575 \\
\hline 员 & -11.69 & 10.57 & 596 & -3.18 & 11.29 & 578 & NA & NA & NA & NA & NA & NA & NA & NA & NA \\
\hline مبر & 6.05 & 11.33 & 5131 & 9.01 & 11.91 & 4910 & NA & NA & NA & NA & NA & NA & NA & NA & NA \\
\hline
\end{tabular}
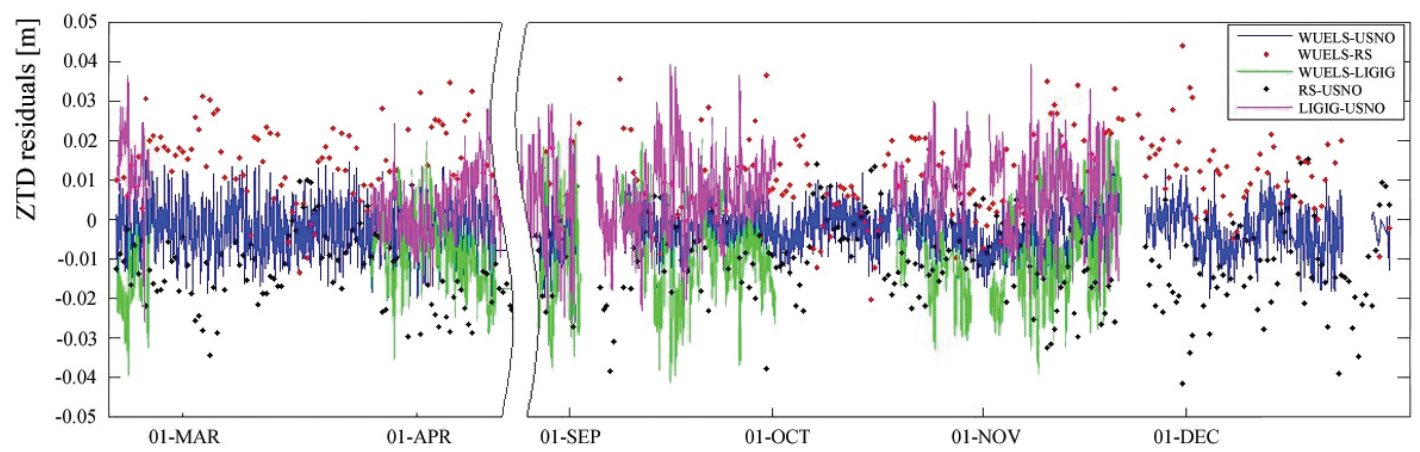

Fig. 3. The results of $Z T D_{\text {WUELS }}-Z T D_{\text {USNO }}, Z T D_{\text {WUELS }}-Z T D_{R S}, Z T D_{\text {WUELS }}-Z T D_{\text {LIGIG }}, Z T D_{R S}-Z T D_{\text {USNO }}, Z T D_{\text {LIGIG }}-Z T D_{\text {USNO }}[\mathrm{m}]$ at WROC station in the period from 20 February 2015 to 31 December 2015

\section{Discussion}

We have conducted several comparisons between various processing modes and between different data sources. The two stations (WROC and BOGI) have data from WUELS and USNO. The accuracy of ZTD from GNSS in NRT is calculated as the standard deviation of $Z T D_{\text {WUELS }}$ - ZTD USNO, which is less than $10 \mathrm{~mm}$. The systematic error (bias) calculated for these stations is less than $3 \mathrm{~mm}$. In Ahmed et al. (2012) similar datasets were compared, i.e., ZTD estimated by the hourly NRT (NRT1H) system at the University of Luxembourg with the IGS Final Troposphere product. The comparison was performed for a oneweek period of data from 7 stations in the IGS permanent network. The overall mean difference and standard deviation is $0.93 \pm 3.99 \mathrm{~mm}$, which is slightly better than in this study (see Table 2). The distribution of the values of the $Z T D$ differences from our data is shown in Fig. 4.

Figure 4 shows that the value of $Z T D_{W U E L S}-Z T D_{U S N O}$ is of normal distribution. For both WROC station and BOGI station we note that the mean value of the ZTD differences is slightly towards the direction of negative values. The right panel indicates that the ZTD differences are correlated with the values of errors in $Z T D\left(m Z T D_{\text {WUELS }}\right)$. At BOGI station, both the differences between $Z T D$ s and $m Z T D_{\text {WUELS }}$ are more diverse than at WROC station. Some outliers, for which the error in ZTD is height, correspond quite well to the height values of differences. However, for some values we have large differences (in the order of $60 \mathrm{~mm}$ ) but still low $m Z T D_{W U E L S}$, which might cause a problem if one were to take only formal errors as a ZTD quality indicator.

Another comparison between $Z T D_{\text {WUELS }}$ and radiosonde data was also made - for all the five stations in Poland. The radiosonde data are available only twice a day (every 12 hours), hence the sample size is significantly smaller than the other data sources. The standard deviation of these data is about $10 \mathrm{~mm}$, however, the bias reaches as much as $13 \mathrm{~mm}$ at the WROL station. Similar standard deviations were obtained by Van der Marel (2004). In that study the GPS ZTD estimates agreed with ZTD from radiosonde at 

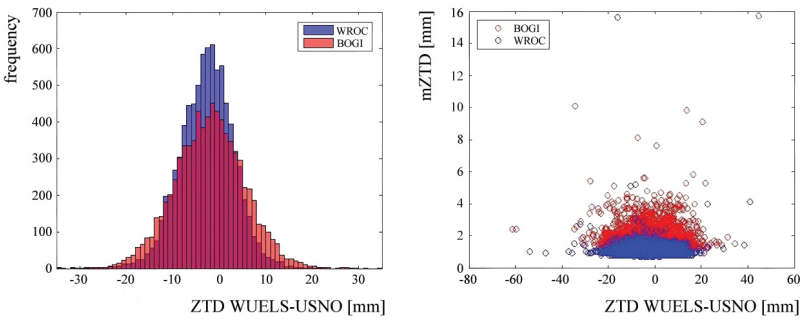

Fig. 4. Distribution of $Z T D_{\text {WUELS }}-Z T D_{\text {USNO }}$ (left panel) and relationship between $Z T D_{\text {WUELS }}-Z T D_{\text {USNO }}[\mathrm{mm}]$ and $m Z T D_{\text {WUELS }}$ $[\mathrm{mm}]$ values (right panel) for WROC and BOGI stations in the period from 20 February 2015 to 31 December 2015

the level of $10 \mathrm{~mm}$, whereas the bias was between 5 and $20 \mathrm{~mm}$, depending on the station and GPS processing centre. In Vespe et al. (2008), the standard deviation of NRT ZTDs was in the range of $5 \mathrm{~mm}$ to $15 \mathrm{~mm}$, when compared to radiosonde observations. In Vedel et al. (2001) the difference $Z T D_{G P S}-Z T D_{R S}=6.0 \pm 11.7 \mathrm{~mm}$. In Pacione and Vespe (2008), the NRT ZTD and radiosonde comparison reveals an overall $Z T D$ bias of about $7 \mathrm{~mm}$ with a standard deviation of $9 \mathrm{~mm}$. We observed that there is no correlation either between height difference (for GNSS and RS stations) and statistic values or between distance and statistical results (not shown).

We also compared ZTDs from WUELS and LIGIG data sources using statistics of all the five stations. The bias at each station is within a range of $5 \mathrm{~mm}$ to $11 \mathrm{~mm}$, whereas the standard deviation is higher than $10 \mathrm{~mm}$. The only station with a very low bias $(0.01 \mathrm{~mm})$ is LEBI, however, the sample size of this station is the lowest. The statistics in Vedel et al. (2001) are slightly better for the bias and worse for the standard deviation. The average offset for GPS ZTD and HIRLAM (NWP model) is $3.2 \pm 17.1$ $\mathrm{mm}$. In Pacione and Vespe (2008), the average bias of ZTD derived from near real-time against the HIRLAM models was about $-4.8 \mathrm{~mm}$ and a standard deviation of $11.5 \mathrm{~mm}$. ZTD of the LIGIG stations is interpolated from the nearest WRF grid node to the GNSS station. Figure 5 (left panel) shows that the bias is lower when the distance between WUELS and LIGIG is larger. If we assume the same meteorological conditions for all WRF nodes - station pairs (which is reasonable) for one year, we may identify some positive correlation between the bias and the height difference, which is shown in Fig. 5 (right panel).

The biases of the ZTDs from the pairs WUELS-RS and WUELS-LIGIG are opposite, and their standard deviations are very close. In order to compare RS and LIGIG results we separated the difference between their ZTDs into two components $-Z H D$ and $Z W D$, which are shown in Fig. 6. The uncertainty of the $Z H D$ modelling, defined as a potential inaccuracy in any phase or activity of the model-
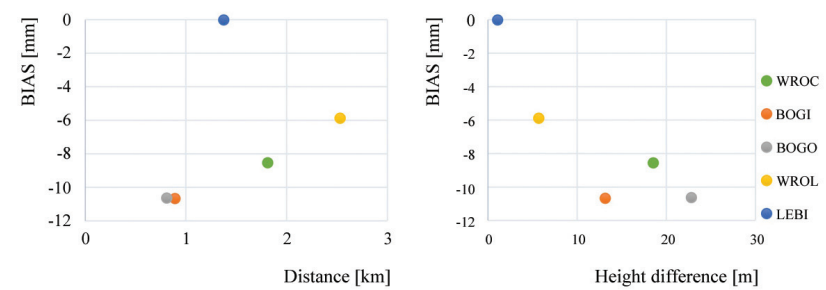

Fig. 5. Dependence of the distance WUELS-LIGIG [km] (left panel, LEBI point exceptional) and the height difference $[\mathrm{m}]$ (right panel) on BIAS [mm] for the period from 20 February 2015 to 31 December 2015

ling process that is due to a lack of knowledge (Oberkampf et al. 2002), is mainly dependent on errors in air pressure measurements. It can be written as (Vey et al. 2010):

$$
\sigma_{Z H D} \approx 0.00228 m \mathrm{hPa}^{-1} \times \sigma_{p}
$$

An error $\sigma_{p}$ in the air pressure of $2 \mathrm{hPa}$ causes an error $\sigma_{Z H D}$ in the modelled hydrostatic delay of $4.6 \mathrm{~mm}$. Systematic discrepancies between $Z H D$ are reported by Vedel et al. (2001), who emphasise that the correction of position offsets between a GNSS antenna and pressure sensor as an altitude difference of $8 \mathrm{~m}$ corresponds to $1 \mathrm{hPa}$, which corresponds to $2.3 \mathrm{~mm}$ in $Z H D$.

The dry component is directly correlated with atmospheric pressure and its value is about $2 \mathrm{~m}$ larger than the value of the wet component. The non-hydrostatic component is in the range of approximately $0.1-0.25 \mathrm{~m}$ and changes rapidly. Figure 6 for WROC station shows that the values of $Z H D_{L I G I G}-Z H D_{R S}$ are higher than $Z W D_{L G I G}-$ $Z W D_{R S}$ values and constant over a year. This means that there is a systematic error in the ZHD computations. On the other hand, the differences between $Z W D_{L G I G}-$ $Z W D_{R S}$ are more scattered and varied over a year. As in Vedel et al. (2001), we notice a much better agreement between hydrostatic delays. $Z W D$ is local and depends on water vapour content and temperature conditions in the troposphere, therefore its value is more difficult to estimate.

We should note that ZTDs statistics change within a year. Figure 7 shows statistical results of the ZTD for the WROC station. This figure indicates the values of $Z T D_{W U E L S}-Z T D_{L I G I G}$ and $Z T D_{W U E L S}-Z T D_{R S}$ are larger than $Z T D_{W U E L S}-Z T D_{U S N O}$ during a whole year. The bias between $Z T D_{W U E L S}$ and $Z T D_{R S}$ is lower in the summer and autumn than in other seasons, whereas the variability of the bias between $Z T D_{\text {WUELS }}$ and $Z T D_{\text {LIGIG }}$ is not possible to assess. Some variability in the statistics is caused by the redeveloping of the WUELS processing engine and the switch from Bernese 5.0 to Bernese 5.2, which was performed from April to August 2012. It is also noticeable 


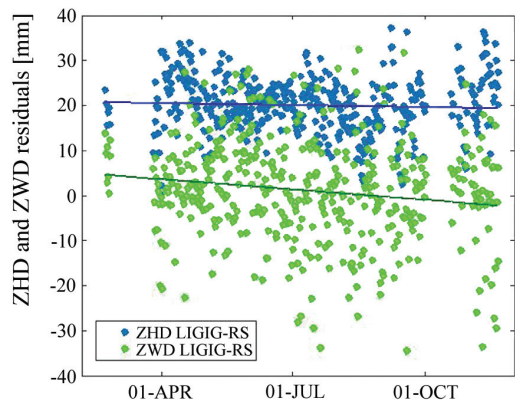

Fig. 6. Comparison between the values of $Z H D_{L I G I G}-Z H D_{R S}$ and $Z W D_{L I G I G}-Z W D_{R S}[\mathrm{~mm}]$ for WROC station in the period from 20 February 2015 to 31 December 2015

that standard deviation values in the WUELS-USNO comparison, in the second part of the year have lower values than previously.

GNSS plays an important role in state-of-the-art forecasting meteorology, using both space-based (Rennie 2012) and ground-based platforms (WMO 2012). The ground-based GNSS observations covered in this manuscript could be potentially applied in: 1) assimilation strategies using nudging (Schraff, Hess 2012), the 3DVar (Bennitt, Jupp 2012) or 4DVar (Poli et al. 2007) approach in regional non-hydrostatic models such as Weather Research and Forecasting (Barker et al. 2012) as it has been reported to improve rain location and intensity predictions; 2) as robust, all-weather, unbiased estimates of integrated water vapour content for climatological studies (Isioye et al. 2015), with growing time series lengths for stations all around the world; 3) in nowcasting applications (Karabatic et al. 2011) that require high-quality integrated water vapour maps with high-update rates across a country, which will help to quickly validate numerical forecasts; 4) as a data source for more sophisticated analysis, such as 4D tomography imaging of severe weather (Manning et al. 2014); 5), as a troposphere correction in SAR processing (Bekaert et al. 2015) and in precise point positioning (Hadaś et al. 2013).

\section{Conclusion}

The presented analysis assesses the quality of zenith total delay obtained from ground-based GNSS, which is computed in near real-time at the Wrocław University of Environmental and Life Sciences. The ZTD statistics from various data sources indicate that the $Z T D_{W U E L S}$ values are the closest to IGS ZTD derived from a precise GNSS solution. In this comparison both bias and standard deviation are the lowest (about $3 \mathrm{~mm}$ and less than $10 \mathrm{~mm}$, respectively). In the case of meteorological observations, quite high systematic errors are also revealed for ZTD values for RS as LIGIG data (5-11 mm for LIGiG and about 10

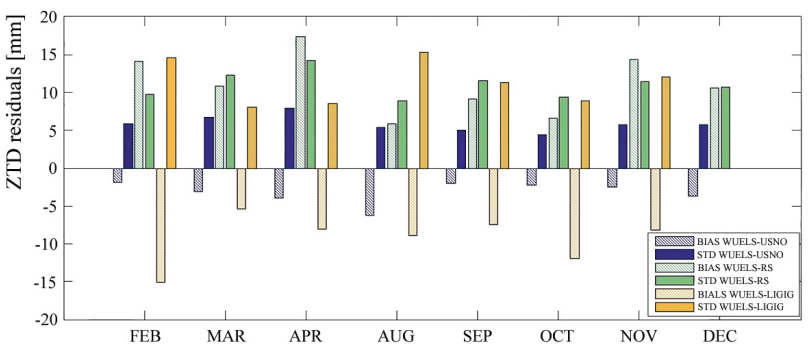

Fig. 7. Monthly bias and standard deviation of $Z T D_{W U E L S}-$ $Z T D_{\text {USNO }}, Z T D_{\text {WUELS }}-Z T D_{R S}, Z T D_{\text {WUELS }}-Z T D_{\text {LIGIG }}, Z T D_{R S}-$ $Z T D_{\text {USNO }}$, ZTD $D_{\text {LIGIG }}-Z T D_{\text {USNO }}[\mathrm{mm}]$ for WROC station in the period from 20 February 2015 to 31 December 2015

$\mathrm{mm}$ for RS). The reason for the bias is currently unknown. Standard deviation of ZTD in WUELS-RS is less than $14 \mathrm{~mm}$, whilst for the WUELS-LIGIG comparison it is slightly greater than $10 \mathrm{~mm}$. The three databases: MaGDA, c-MaGDA and LIGiG, were launched for different purposes. Each of them collects data as soon as it is available. The MaGDA contains both meteorological and GNSS data (in near real-time mode) for about 295 GNSS stations in Poland. c-MaGDA stores IGS ZTD from precise GNSS solution data for five stations in Poland (with three weeks' latency) and radiosonde ZTD (available twice a day), which are interpolated to the nearest GNSS station. Lastly, selected data from WRF at the location of GNSS stations are stored in the LIGiG database, which is updated every 6 hours.

According to the EIG EUMETNET GNSS Water Vapour Programme (E-GVAP-II) Product Requirements Document (E-GVAP 2010), in order to assimilate the NRT ZTD Product into NWP models, it should have $15 \mathrm{~mm}$ threshold accuracy, whilst the target value is $10 \mathrm{~mm}$. The timeliness of the data (maximum difference from observation to user) is also very important for meteorological forecasting, for which the threshold value is 2 hours and the target value is $1.5 \mathrm{~h}$. Considering the NRT ZTD WUELS quality assessment, we state that this product meets the requirements for assimilating into NWP models.

\section{Acknowledgments}

The authors would like to thank the GNSS\&Meteo Working Group Wrocław University of Environmental and Life Sciences, the Institute of Geodesy and Geoinformatics (www.igig.up.wroc.pl/igg) for providing ZTD derived from GNSS, the Department of Climatology and Atmosphere Protection (http://www.meteo.uni.wroc.pl/), the University of Wrocław for providing a NWP model and meteorological data, the Institute of Meteorology and Water Management (www.imgw.pl) for providing radiosonde data. The computations were performed courtesy of the Wrocław Center of Networking and Supercomput- 
ing (http://www.wcss.wroc.pl): computational grant using Matlab Software License No: 101979. This research was supported by the SPIN-LAB project financed with the European Regional Development Fund in the framework of the Innovative Economy funding stream and the State budget (No POIG.02.03.00-02-027/13), GNSS observations as a numerical weather prediction data source, a way forward to enhanced forecast quality Number (MSHE code): UMO-2013/11/D/ST10/03473. The computations of the WRF model forecasts were performed courtesy of the Wroclaw Center of Networking and Supercomputing (http://www.wcss.wroc.pl): computational grant no 170 .

Bibliography

Ahmed F., Teferle N., Bingley R., 2012, An evaluation of realtime, near real-time and post-processed Zenith Total Delay estimates, IGS Workshop, July 23-27, Olsztyn, Poland

Barker D., Huang X.Y., Liu Z., Auligné T., Zhang X., Rugg S., Ajjaji R., Bourgeois A., Bray J., Chen Y., Demirtas M., Guo Y.R., Henderson T., Huang W., Lin H.Ch., Michalakes J., Rizvi S., Zhang X., 2012, The weather research and forecasting model's community variational/ensemble data assimilation system: WRFDA, Bulletin of the American Meteorological Society, 93 (6), 831-843, DOI: 10.1175/ BAMS-D-11-00167.1

Bekaert D.P.S., Hooper A., Wright T.J., 2015, A spatially variable power law tropospheric correction technique for InSAR data, Journal of Geophysical Research: Solid Earth, 120 (2), 13451356, DOI: 10.1002/2014JB011557

Bennitt G.V., Jupp A., 2012, Operational assimilation of GPS Zenith Total Delay observations into the Met Office numerical weather prediction models, Monthly Weather Review, 140 (8), 2706-2719, DOI: 10.1175/MWR-D-11-00156.1

Boehm J., Niell A., Tregoning P., Schuh H., 2006, Global Mapping Function (GMF): A new empirical mapping function based on numerical weather model data, Geophysical Research Letters, 33 (7), L07304, DOI: 10.1029/2005GL025546

Bosy J., Graszka W., Leończyk M., 2007, ASG-EUPOS. A multifunctional precise satellite positioning system in Poland, European Journal of Navigation, 5 (4), 2-6

Bosy J., Kapłon J., Rohm W., Sierny J., Hadaś T., 2012, Near real-time estimation of water vapour in the troposphere using ground GNSS and the meteorological data, Annales Geophysicae, 30, 1379-1391, DOI: 10.5194/angeo-30-1379-2012

Byram S, Hackman C., 2012, Computation of the IGS Final Troposphere product by the USNO, IGS Workshop, July 23-27, Olsztyn, Poland

Dach R., Hugentobler U., Fridez P., Meindl M., 2007, Bernese GPS Software, Astronomical Institute, University of Bern, 640 pp.
Dach R., Lutz S., Walser P., Fridez P., 2015, Bernese GNSS Software Version 5.2. User manual, Astronomical Institute, University of Bern, Bern Open Publishing, 884 pp., DOI: 10.7892/boris. 72297

Dow J.M., Neilan R.E., Rizos C., 2009, The International GNSS Service in a changing landscape of Global Navigation Satellite Systems, Journal of Geodesy, 83 (3-4), 191-198, DOI: 10.1007/s00190-008-0300-3

E-GVAP, 2010, EIG EUMETNET GNSS Water Vapour Programme (E-GVAP-II). Product Requirements Document. Technical Report, Met Office, 36 pp., available at: http:// egvap.dmi.dk/support/formats/egvap_prd_v10.pdf (data access 09.09.2016)

Hackman Ch., Guerova G., Byram S., Dousa J., Hugentobler U., 2015, International GNSS Service (IGS) Troposphere Products and Working Group Activities, conference material, FIG Working Week, 17-21 May Sofia, Bulgaria, 14 pp.

Hadaś T., Kaplon J., Bosy J., Sierny J., Wilgan K., 2013, Nearreal-time regional troposphere models for the GNSS precise point positioning technique, Measurement Science and Technology, 24 (5), 055003

Hitsch U., 2004, Comparison of GPS and Radiosonde Derived Humidity Values, M.S. thesis, Institute of Meteorology, University of Vienna

Hofmann-Wellenhof B., Lichtenegger H., Wasle E., 2008, GNSS - global navigation satellite systems: GPS, GLONASS, Galileo, and more, Springer-Verlag Wien, 518 pp.

Hoque M.M., Jakowski N., 2007, Higher order ionospheric effects in precise GNSS positioning, Journal of Geodesy, 81 (4), 259-268, DOI: 10.1007/s00190-006-0106-0

Hordyniec P., Bosy J., Rohm W., 2015, Assessment of errors in Precipitable Water data derived from Global Navigation Satellite System observations, Journal of Atmospheric and Solar-Terrestrial Physics, 129, 69-77, DOI: 10.1016/j. jastp.2015.04.012

Isioye O.A., Combrinck L., Botai J.O., Munghemezulu C., 2015, The potential for observing African weather with GNSS remote sensing, Advances in Meteorology, 2015, 16 pp., DOI: $10.1155 / 2015 / 723071$

Karabatić A., Weber R., Haiden T., 2011, Near real-time estimation of tropospheric water vapour content from ground based GNSS data and its potential contribution to weather nowcasting in Austria, Advances in Space Research, 47 (10), 1691-1703, DOI: 10.1016/j.asr.2010.10.028

Kleijer F., 2004, Troposphere modelling and filtering for precise GPS levelling, Ph. D. thesis, Mathematical Geodesy and Positioning, Delft University of Technology, $282 \mathrm{pp}$.

Landau H., Vollath U., Chen X., 2002, Virtual reference station systems, Journal of Global Positioning Systems, 1 (2), 137-143

Manning T., Rohm W., Zhang K., Hurter F., Wang C., 2014, Determining the $4 \mathrm{D}$ dynamics of wet refractivity using GPS to- 
mography in the Australian region, [in:] Earth on the Edge: Science for a Sustainable Planet, Ch. Rizos, P. Willis (eds.), Springer Berlin Heidelberg, 41-49

Möller G., Böhm J., Weber R., 2014, Comparison of IGS final troposphere estimates with ray-traced delays, IGS Workshop, June 23-27, Pasadena, CA, USA

NCAR, 2016, The NCAR Command Language (Version 6.3.0). Boulder, Colorado: UCAR/NCAR/CISL/TDD, DOI: 10.5065/D6WD3XH5

Niell A.E., 2000, Improved atmospheric mapping functions for VLBI and GPS, Earth Planets Space, 52 (10), 699-702, DOI: 10.1186/BF03352267

Norman R.J., Le Marshall J., Rohm W., Carter B.A., Kirchengast G., Alexander S., Liu C., Zhang K., 2015, Simulating the impact of refractive transverse gradients resulting from a severe troposphere weather event on GPS signal propagation, IEEE Journal of Selected Topics in Applied Earth Observations and Remote Sensing, 8 (1), 418-424, DOI: 10.1109/ JSTARS.2014.2344091

Oberkampf W.L., DeLand S.M., Rutherford B.M., Diegert K.V., Alvin K.F., 2002, Error and uncertainty in modeling and simulation, Reliability Engineering \& System Safety, 75 (3), 333-357, DOI: 10.1016/S0951-8320(01)00120-X

Pacione R., Vespe F., 2008, Comparative studies for the assessment of the quality of near-real-time GPS-derived atmospheric parameters, Journal of Atmospheric and Oceanic Technology, 25, 701-714, DOI: 10.1175/2007JTECHA935.1

Poli P., Moll P., Rabier F., Desroziers G., Chapnik B., Berre L., Healy S.B., Andersson E., El Guelai F.Z., 2007, Forecast impact studies of zenith total delay data from European near real-time GPS stations in Météo France 4DVAR, Journal of Geophysical Research: Atmospheres, 112 (D6), DOI: 10.1029/2006JD007430

Rennie M., 2012, Report on the Assimilation of GPS Radio Occultation data into the Met Office global model, Forecasting Research Technical Report No. 510, 63 pp.

Rohm W., Yuan Y., Biadeglgne B., Zhang K., Le Marshall J., 2014, Ground-based GNSS ZTD/IWV estimation system for numerical weather prediction in challenging weather conditions, Atmospheric Research, 138, 414-426, DOI: 10.1016/j. atmosres.2013.11.026
Saastamoinen J., 1972, Atmospheric correction for the troposphere and stratosphere in radio ranging of satellites, [in:] The use of the Artificial Satellites for Geodesy, S.W. Henriksen, A. Mancini, B.H. Chovitz (eds.), American Geophysical Union, Washington, USA, 247-251, DOI: 10.1029/ GM015p0247

Schraff C., Hess R., 2012, A description of the nonhydrostatic COSMO-Model. Part III: Data Assimilation, Deutscher Wetterdienst, Offenbach, 93 pp.

Solheim F., Vivekanandan J., Ware R., Rocken C., 1999, Propagation delays induced in GPS signals by dry air, water vapor, hydrometeors, and other particules, Journal of Geophysical Research, 104 (D8), 9663-9670

Van der Marel H., 2004, COST-716 demonstration project for the near real-time estimation of integrated water vapour from GPS, Physics and Chemistry of the Earth. Parts A/B/C, 29 (2-3), 187-199, DOI: 10.1016/j.pce.2004.01.001

Vedel H., Mogensen K.S., Huang X.Y., 2001, Calculation of zenith delays from meteorological data, comparison of NWP model, radiosonde and GPS delays, Physics and Chemistry of the Earth, 26 (6-8), 497-502, DOI: 10.1016/S14641895(01)00091-6

Vespe F., Pacione R., Pace B., 2008, Accuracy of regional nearreal time GPS ZTD \& site coordinate estimates versus IGS Ultra-Rapid products, IGS Workshop, Miami Beach, Florida, USA

Vey S., Dietrich R., Rülke A., Fritsche M., Steigenberger P., Rothacher M., 2010, Validation of Precipitable Water Vapor within the NCEP/DOE Reanalysis Using Global GPS Observations from One Decade, Journal of Climate, 23, 1675 1695, DOI: 10.1175/2009JCLI2787.1

WMO, 2012, WMO Integrated Global Observing System. Final report of the Fifth WMO Workshop on the Impact of Various Observing Systems on Numerical Weather Prediction, WMO Technical Repoirt 2012-1, 25 pp., available at: www.wmo. int/pages/prog/www/OSY/Meetings/NWP5_Sedona2012/ Final_Report.pdf (data access 09.09.2016)

Zheng L., Sun J., Zhang X., Liu C., 2013, Organizational modes of mesoscale convective systems over central East China, Weather and Forecasting, 28 (5), 1081-1098, DOI: 10.1175/ WAF-D-12-00088.1 